Original article

\title{
The treatment gap for mental disorders and associated factors in the Czech Republic
}

\author{
Anna Kagstrom ${ }^{\mathrm{a}}$, Aneta Alexova ${ }^{\mathrm{a}}$, Eva Tuskova ${ }^{\mathrm{a}}$, Zsófia Csajbók ${ }^{\mathrm{a}, \mathrm{b}}$, Georg Schomerus ${ }^{\mathrm{c}}$, \\ Tomas Formanek ${ }^{\mathrm{a}}$, Karolína Mladáa ${ }^{\text {, Petr Winkler }}{ }^{\mathrm{a}, \mathrm{d}}$, Pavla Cermakova ${ }^{\mathrm{a}, \mathrm{e}, *}$ \\ a National Institute of Mental Health, Klecany, Czech Republic \\ ${ }^{\mathrm{b}}$ Faculty of Science, Charles University Prague, Czech Republic \\ ${ }^{\mathrm{c}}$ Department of Psychiatry, University of Leipzig, Leipzig, Germany \\ ' Health Service and Population Research Department, Institute of Psychiatry, Psychology and Neurosciences, King's College London, United Kingdom \\ e Third Faculty of Medicine, Charles University Prague, Czech Republic
}

\section{A R T I C L E I N F O}

\section{Article history:}

Received 4 March 2019

Received in revised form 11 April 2019

Accepted 12 April 2019

Available online 19 April 2019

\section{Keywords:}

Mental disorders

Epidemiology

Central and Eastern Europe

Treatment gap

\begin{abstract}
A B S T R A C T
Objectives: To assess the extent of the treatment gap for mental disorders in the Czech Republic, determine factors associated with the utilization of mental health services and explore what influences willingness to seek mental health care.

Methods: Data from the CZEch Mental health Study, a nationally representative study of communitydwelling adults in the Czech Republic were used. The Mini International Neuropsychiatric Interview assessed the presence of mental disorders. 659 participants with current affective, anxiety, alcohol use and substance use disorders were studied.

Results: The treatment gap for mental disorders ranged from $61 \%$ for affective to $93 \%$ for alcohol use disorders. Mental health service use was associated with greater disability (OR 1.04; 95\% CI 1.02-1.05; $\mathrm{p}<0.001$ ), female gender (OR 3.31; 95\% CI 1.97-5.57; $\mathrm{p}<0.001$ ), urban residence (OR 1.84; 95\% CI 1.12-3.04; $\mathrm{p}<0.05$ ) and a higher number of somatic diseases (OR 1.32; 95\% CI 1.03-1.67; p < 0.05). Self-identification as having a mental illness was associated with greater willingness to seek a psychiatrist and a psychologist. Conclusions: The treatment gap for mental disorders is alarmingly high in the Czech Republic. Interventions to decrease it should target in particular rural areas, men and people with low self-identification as having a mental illness.
\end{abstract}

(c) 2019 Elsevier Masson SAS. All rights reserved.

\section{Background}

An interest in mental health has only recently increased in the Czech Republic after many years of neglect [1,2]. The Czech government is currently developing and implementing a reform that aims to modernize the care of patients affected with mental disorders. It is estimated that approximately every fifth person living in the Czech Republic is currently affected by an affective, anxiety, alcohol or substance use disorder [3]. These mental disorders have a profound effect on the individuals' quality of life, psycho-social functioning, occurrence and management of somatic comorbidities as well as life expectancy [3,4]. A large gap between the number of affected persons and those who receive evidence-based treatment may strongly contribute to unfavourable outcomes [5]. The treatment gap in mental

\footnotetext{
* Corresponding author at: National Institute of Mental Health, Topolová 748, 250 67, Klecany Czech Republic.

E-mail address: Pavla.Cermakova@nudz.cz (P. Cermakova).
}

health care represents the disparity between the true prevalence of a disorder and the treated proportion of individuals affected by it [5].

Efforts to decrease this gap have been recognized around the globe as a major public health challenge for the 21st century [5]. Globally, the overall treatment gap for mental disorders exceeds $50 \%$, rising up to $90 \%$ in low and middle income countries [5]. Causes for the treatment gap are multi-faceted, and include affected individuals, clinicians and societal factors [6,7]. Awareness of mental health symptoms and relating them to a potential mental health problem has been shown to be an important predictor of perceived need and help-seeking intentions in persons with untreated mental disorders [8]. However, there is no existing evidence assessing the extent of the treatment gap in the Czech Republic.

Estimates of the treatment gap for mental disorders in the Czech Republic are necessary to inform appropriate resource allocation within national mental health services (MHS). Considering the knowledge gap surrounding mental health within the region of Central and Eastern Europe $[9,10]$ and the ongoing development of new MHS in the Czech Republic, we aimed to analyse data from a 
nationally representative study of mental disorders in the Czech Republic to 1 ) assess the extent of the treatment gap for mental disorders in the Czech Republic; 2 ) determine factors associated with the utilization of MHS; and 3) explore factors, which influence willingness to seek MHS in individuals that are currently affected with mental disorders but have not yet sought help.

\section{Methods}

\subsection{Source of data}

We performed a cross-sectional study with participants in the CZEch Mental health Study (CZEMS). CZEMS is a population-based survey launched within the context of the ongoing mental health care reform with the aim to determine the prevalence of mental disorders and the associated treatment gap. The study rationale, design and methods have been previously described in detail [3]. Briefly, a two-stage sampling was used in order to arrive at a sample of nationally representative community-dwelling adults. A random sample of 850 voting districts was selected in the first stage and a random starting address was chosen in the second one. The study participants (minimum age of 18 years) were then chosen using a random-route-procedure and a first-birthdaymethod. Centrally trained staff conducted face-to-face paper and pencil interviews (PAPI). The prevalence of mental disorders was assessed through the fifth version of Mini International Neuropsychiatric Interview (M.I.N.I.) [11].

In the present analysis, we studied individuals classified with the following current mental disorders: affective disorders (major depressive episode, dysthymia, hypomanic episode and manic episode); anxiety disorders (panic disorder, agoraphobia, obsessive-compulsive disorder, post-traumatic stress disorder, social anxiety disorder and generalized anxiety disorder); alcohol use disorders (alcohol abuse and alcohol dependence) and substance use disorders (abuse and dependence on stimulants, narcotics, inhalants, cannabis, tranquilizers, psychedelics and other drugs). Because of the well-known high prevalence of alcohol consumption in the Czech Republic [12], we present alcohol use disorders and substance use disorders separately. Psychotic disorders are not included in this analysis to enhance validity of our treatment gap calculation, as previous studies show strong overestimation of psychosis in lay-administered interviews [13,14].

All participants provided an oral informed consent after being informed about the purpose of the study and the storage and use of the data. Data were anonymised before analysis by removing direct identifiers.. This study was approved by the Ethics Committee of the National Institute of Mental Health, Czech Republic (reference number 97/18).

\subsection{Treatment gap}

The treatment gap for mental disorders has widely been calculated as the proportion of individuals that do not utilize MHS out of the persons that have prevalent disorders [15]. We operationalized utilization of MHS with the following: Participants were asked whether they sought medical or other professional help (psychiatrist / psychologist / general practitioner / other) due to their mental health during the past 12 months. The frequency of persons who reported having sought help from a psychiatrist, psychologist, general practitioner (GP) or another professional included in the health care system of the Czech Republic is considered the frequency of MHS utilization. The treatment gap in the present study is thus defined as the proportion of persons having utilized MHS during the past 12 months out of the persons that have been classified with a current mental disorder.

\subsection{Willingness to seek mental health care}

As a part of the PAPI, participants were asked which professional they would seek help from and the likelihood that they would contact them if they experienced mental health problems. Possible answers were "definitely yes", "rather yes", "rather not”, “definitely not” for 5 groups of professionals: 1. psychiatrist, 2. psychologist, 3. GP, 4. healer/alternative therapist, 5 . other. We operationalized willingness to seek mental health care if the participants answered "definitely yes or rather yes" to three professionals: psychiatrist, psychologist and GP. Within this study, we do not consider healers/ alternative therapists as health professionals as they do not belong to the official health care system of the Czech Republic, and the purpose of the study is to inform the reform of MHS.

\subsection{Covariates}

Covariates were identified according to literature $[6,7,16-18]$ as socio-demographic, social and health-related characteristics associated with MHS use and willingness to seek mental health care. Socio-demographic characteristics included age, gender, highest completed education, location of residence and occupation status. Social characteristics were marital status, children, informal social contact (defined as less than daily informal contact with relatives, friends, neighbours and members of common household) and number of stressful life events during the past year (out of 23 defined events). Health-related characteristics concerned physical inactivity, diet due to health reasons, smoking and total number of somatic diseases (defined as diseases they are currently treated for or were hospitalized/treated for during the past 12 months). In addition, The World Health Organization Disability Assessment Schedule (WHODAS) [19] measured disability and the SelfIdentification as Having a Mental Illness (SELFI) scale was administered to assess self-identification within a group of persons having a mental illness [20]. Details about the covariates are described in detail in the Supplement.

\subsection{Analytical sample}

From 3306 respondents in CZEMS, 659 individuals were classified as having a current affective, anxiety, alcohol use or substance use disorder. Of those, 113 individuals reported having sought medical or other professional help (psychiatrist / psychologist / GP / other) due to their mental health during the past 12 months, while 546 had not. The most commonly reported professional contacted was GP $(n=66)$, followed by psychiatrist $(n=63)$, psychologist $(n=30)$ and other $(n=9$ : neurologist $2 x$, healer $2 x$, psychotherapist, kinesiologist, homeopathist, physiotherapist, and witch). From the nine persons who reported having sought a professional in the category "other", four sought also a GP, while five did not. Those individuals contacted a neurologist $(2 x)$, psychotherapist, healer and a witch. We considered the two who contacted a healer and a witch as individuals who had not utilized MHS as there is no systemic collaboration amongst traditional healers and MHS in the Czech Republic. The final sample size thus consisted of 111 users of MHS and 548 non-users (flowchart presented in Fig. 1).

\subsection{Statistical analysis}

We present descriptive data as frequency ( $\mathrm{n}, \%$ ), means \pm standard deviation (SD) or median and interquartile range (IQR), where appropriate. To compare characteristics of the respondents between the users and non-users of MHS, we used $\chi^{2}$ test for binary variables and independent samples $t$-test or Mann-Whitney test for continuous variables. We performed multivariable logistic regression to estimate odds ratio (OR) with 95\% confidence interval 


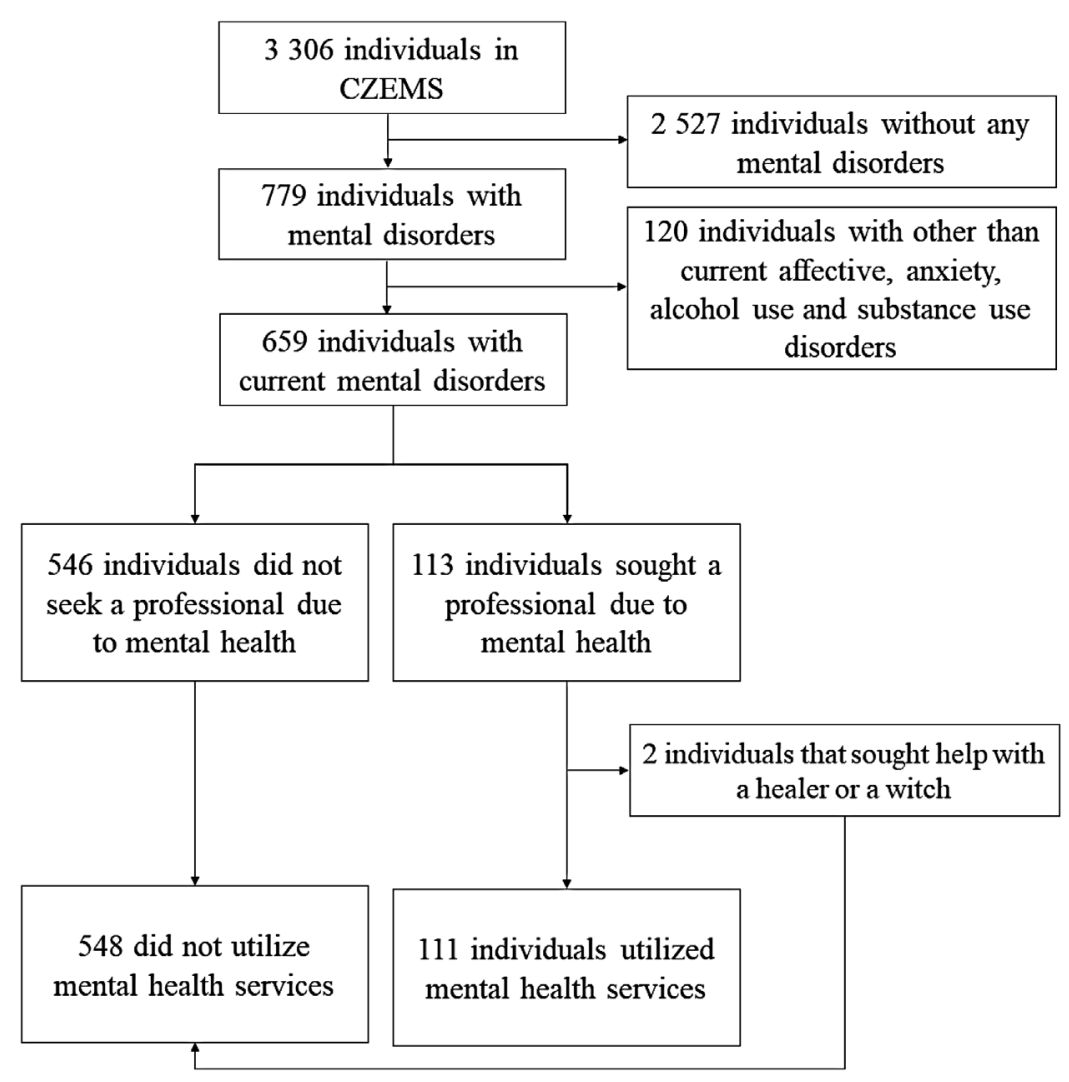

Fig. 1. Selection of the analytical sample. CZEMS, CZEch Mental health Study.

(CI) for the association of respondents' characteristics with the utilization of MHS. Variables that were statistically significant in the univariate analysis at the level of $\mathrm{p}<0.05$ were automatically included in the multivariable analysis. Further, we added in a stepwise fashion also variables into the model that were not statistically significant in the univariate analysis and kept them in the final model if they fulfilled two conditions: 1) they improved the pseudo $\mathrm{R}^{2}$ of the model and 2) were associated with the dependent variable at the level of $\mathrm{p}<0.05$ in the final model.

Further, we examined the SELFI scale's factor structure using confirmatory factor analysis, assuming that the underlying 'selfidentification as having a mental illness' latent factor predicts the variance of the SELFI items. We applied structural equation modelling, which enables simultaneous assessment of all hypothesized paths, to estimate with logistic regression the OR with $95 \%$ $\mathrm{CI}$ for the association of the respondents characteristics (SELFI latent factor and other covariates) with willingness to seek a GP, a psychologist, and a psychiatrist. Structure of the path-model is presented in Supplemental Fig. S1. Analyses were performed using STATA (Version 15.1) and MPlus (Version 8).

\section{Results}

We studied 659 individuals (on average 47 years old, 48\% women) affected by a current affective $(n=183)$, anxiety $(n=244)$, alcohol use $(n=350)$ or substance use $(n=94)$ disorder. From those, $26 \%$ had two or more co-occurring mental disorders. Only $17 \%$ out of the whole sample utilized MHS during the past year, leaving a total treatment gap of $83 \%$. Stratifying by diagnosis, the treatment gap was $61 \%$ for affective, $69 \%$ for anxiety, $77 \%$ for substance use and $93 \%$ for alcohol use disorders (Fig. 2).
Overall, MHS users were older and more frequently women (Table 1). They were to a greater extent without work and a partner, had less social contact and experienced more stressful life events. In addition, they were to a larger extent physically inactive, on a diet due to health reasons, suffered from more somatic comorbidities and were more disabled. Multivariable analysis demonstrated that utilization of MHS was independently associated with four variables: higher disability $(p<0.001)$, female gender $(p<0.001)$, urban residence $(p<0.05)$ and a higher number of somatic diseases $(\mathrm{p}<0.05$; Table 2$)$.

Among those who had not used MHS during the last 12 months, female gender ( $O R=1.96 ; 95 \%$ CI 1.31-2.92), rural residence (results for urban residence: OR $=0.67 ; 95 \%$ CI 0.46 to 0.96$)$ and higher disability ( $\mathrm{OR}=2.02 ; 95 \% \mathrm{CI} 1.30-3.14)$ were associated with greater willingness to seek a psychiatrist. Female gender $(\mathrm{OR}=1.66 ; 95 \% \mathrm{CI} 1.10-2.50)$, younger age $(\mathrm{OR}=0.98 ; 95 \%$ CI 0.97 to 0.996 ), higher education (results for basic/vocational education: $\mathrm{OR}=0.55 ; 95 \% \mathrm{CI} 0.37$ to 0.82 ) and non-smoking (results for smokers: $\mathrm{OR}=0.65 ; 95 \%$ CI 0.43 to 0.98 ) were associated with willingness to seek a psychologist. On the contrary, higher number of somatic diseases (OR $=1.37 ; 95 \% \mathrm{CI}$ $1.05-1.78)$ and higher age (OR=1.04; $95 \%$ CI 1.01-1.04) were associated with willingness to seek a GP. A one point increase in self-identification of having a mental illness (SELFI) was associated with both greater willingness to seek a psychiatrist $(\mathrm{OR}=1.30 ; 95 \% \mathrm{CI} 1.03-1.64)$ and a psychologist $(\mathrm{OR}=1.61 ; 95 \% \mathrm{CI}$ 1.26-2.06), but not a GP (Table 3).

\section{Discussion}

In the present study based on a nationally representative sample of adults in the Czech Republic, we found that the 
Affective disorders

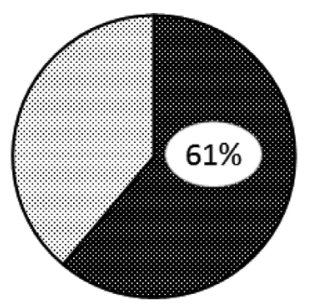

Substance use disorders

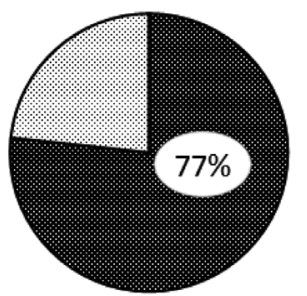

Anxiety disorders

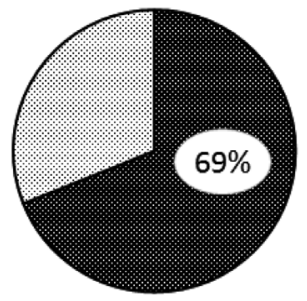

Alcohol use disorders

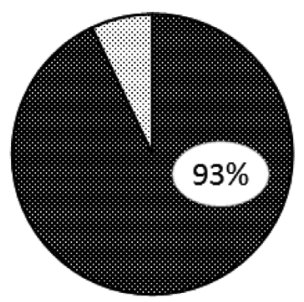

Treatment gap (\%)

Fig. 2. Treatment gap for mental disorders in the Czech Republic: the CZEch Mental health Study (CZEMS).

Table 1

Characteristics of participants by utilization of mental health services $(n=659)$.

\begin{tabular}{|c|c|c|c|}
\hline & $\begin{array}{l}\text { Service users } \\
(\mathrm{n}=111)\end{array}$ & $\begin{array}{l}\text { Service non-users } \\
(\mathrm{n}=548)\end{array}$ & $\mathrm{p}$ value \\
\hline \multicolumn{4}{|l|}{ Socio-demographic characteristics } \\
\hline Age, mean $\pm S D$ & $51.9 \pm 19.2$ & $46.1 \pm 17.2$ & 0.002 \\
\hline Women, n (\%) & $85(77)$ & $231(42)$ & $<0.001$ \\
\hline Basic or vocational education, $\mathrm{n}(\%)$ & $72(65)$ & $321(59)$ & 0.218 \\
\hline Urban residence, $\mathrm{n}(\%)$ & $74(67)$ & $312(57)$ & 0.058 \\
\hline No current work, n (\%) & $28(26)$ & $67(12)$ & $<0.001$ \\
\hline \multicolumn{4}{|l|}{ Social characteristics } \\
\hline No partner, n (\%) & $62(56)$ & $245(45)$ & 0.032 \\
\hline Children, $\mathrm{n}(\%)$ & $83(75)$ & $394(72)$ & 0.536 \\
\hline Little informal social contact, $\mathrm{n}(\%)$ & $54(49)$ & $174(32)$ & 0.001 \\
\hline Stressful life events $(\geq 4), \mathrm{n}(\%)$ & $68(61)$ & $267(49)$ & 0.016 \\
\hline \multicolumn{4}{|l|}{ Health-related characteristics } \\
\hline Physical inactivity, n (\%) & $83(75)$ & $326(60)$ & 0.002 \\
\hline Diet due to health reasons & $32(29)$ & $107(20)$ & 0.028 \\
\hline Smoker, n (\%) & $59(53)$ & $339(62)$ & 0.087 \\
\hline
\end{tabular}

$\mathrm{SD}$, standard deviation; IQR, interquartile range.

Table 2

Associations of participants' characteristics with utilization of mental health services $(n=659)$.

\begin{tabular}{ll}
\hline & OR $(95 \% \mathrm{CI})$ \\
\hline Age & $0.99(0.97 ; 1.00)$ \\
Women & $3.31(1.97 ; 5.57)^{* *}$ \\
Urban residence & $1.84(1.12 ; 3.04)^{*}$ \\
No current work & $1.75(0.95 ; 3.21)$ \\
No partner & $1.43(0.87 ; 2.34)$ \\
Little informal social contact & $1.03(0.60 ; 1.76)$ \\
Stressful life events $(\geq 4)$ & $0.97(0.59 ; 1.58)$ \\
Physical inactivity & $1.58(0.91 ; 2.73)$ \\
Diet due to health reasons & $0.99(0.56 ; 1.75)$ \\
Number of somatic diseases & $1.32(1.03 ; 1.67)^{*}$ \\
WHODAS score & $1.04(1.02 ; 1.05)^{* *}$ \\
\hline
\end{tabular}

OR, odds ratio; CI, confidence interval; WHODAS, The World Health Organization Disability Assessment Schedule.

${ }^{*} p<0.05$.

$p<0.001$ treatment gap for mental disorders ranged from $61 \%$ for affective disorders up to an exceptionally high rate of $93 \%$ for alcohol use disorders. Professionals most commonly approached due to mental health problems were GPs. MHS were utilized most by urban residents, women, persons with higher disability, and individuals with more somatic comorbidities. In those not using MHS, self-identification as having a mental illness was associated with greater willingness to seek mental heal care with a psychiatrist and a psychologist.

The treatment gap for affective disorders (61\%) is slightly higher in comparison with the global median treatment gap for affective disorders around the world (50-56\%), but much higher than the World Health Organization (WHO) regional estimates for Europe (40-45\%) [15]. On the contrary, for anxiety disorders (69\%), the gap is slightly lower than the global estimate (72\%) [21], but higher than the WHO regional estimates for Europe, which reach from $25 \%$ for obsessive-compulsive disorders to $62 \%$ for generalized 
Table 3

Full path model for factors associated with willingness to seek mental health care $(n=548)$.

\begin{tabular}{lll}
\hline & OR $(95 \% \mathrm{CI})$ & \multicolumn{1}{c}{ Psychologist } \\
\cline { 2 - 3 } & Psychiatrist & $0.98(0.97 ; 0.996)^{*}$ \\
\hline Age & $1.00(0.98 ; 1.01)$ & $1.66(1.10 ; 2.50)^{*}$ \\
Women & $1.96(1.31 ; 2.92)^{*}$ & $0.55(0.37 ; 0.82)^{*}$ \\
Basic or vocational education & $0.79(0.54 ; 1.17)$ & $0.99(0.68 ; 0.44)$ \\
Urban residence & $0.67(0.46 ; 0.96)^{*}$ & $0.60(0.33 ; 1.10)$ \\
No current work & $0.63(0.35 ; 1.15)$ & $0.85(0.56 ; 1.30)$ \\
No partner & $0.94(0.62 ; 1.42)$ & $1.19(0.68 ; 2.06)$ \\
Children & $1.24(0.71 ; 2.14)$ & $0.90(0.57 ; 1.41)$ \\
Little informal social contact & $0.66(0.42 ; 1.02)$ & $0.95(0.64 ; 1.41)$ \\
Stressful life events $\geq 4)$ & $1.02(0.69 ; 1.50)$ & $0.71(0.46 ; 1.07)$ \\
Physical inactivity & $0.67(0.44 ; 1.02)$ & $0.88(0.53 ; 1.47)$ \\
Diet due to health reasons & $0.66(0.40 ; 1.09)$ & $0.65(0.43 ; 0.98)^{*}$ \\
Smoker & $0.68(0.45 ; 1.01)$ & $1.10(0.88 ; 1.38)$ \\
Number of somatic diseases & $1.10(0.88 ; 1.38)$ & $1.18(0.65 ; 2.12)$ \\
High disability & $2.02(1.30 ; 3.14)^{*}$ & $0.75(0.49 ; 1.12)$ \\
SELFI & $1.30(1.03 ; 1.64)^{*}$ & $0.74(0.43 ; 0.28)$ \\
\hline SELF & $0.76(0.49 ; 1.18)$ \\
$1.21(0.81 ; 1.79)$ & $0.86(0.57 ; 1.31)$ \\
& $0.98(0.59 ; 1.63)$ \\
\end{tabular}

SELFI, self-identification as having a mental illness; OR, odds ratio; CI, confidence interval; GP, general practitioner.

${ }^{*} p<0.05$.

$p<0.001$.

anxiety disorders [15]. The treatment gap for alcohol use disorders (93\%) is relatively high in comparison with the global average, where $93 \%$ is estimated for alcohol abuse and $78 \%$ for alcohol dependence [15]; however, our result is fairly consistent with the WHO regional estimate for Europe (92\%). The treatment gap for substance use disorders (77\%) is lower in comparison to the global estimate (83\%) as presented by United Nations Office for Drugs and Crime [22]. However, the validity of the discrepancies in crossnational comparisons may be lower given the variation in methods used for estimating mental disorders.

Our finding that utilization of MHS was associated with higher disability and more somatic comorbidities is in line with a systematic review conducted by Twomey et al. [6] and suggests that higher severity of symptoms causing more disability drives help seeking. Contact with GPs and physicians who treat predominantly somatic diseases enables capturing people with mental health problems because their symptoms may be recognized by them. In accordance with literature [23], we found that men less often use MHS and are less willing to seek help, which likely reflects conformity to traditional social masculine norms fostering a culture where both men and women carry negative attitudes towards males' help-seeking [24]. The role of age in service consumption and willingness to seek help is less clear, with studies providing inconsistent results [25-27]. In the present study, we did not find any association between age and MHS use in the Czech population. We speculate that this inconclusiveness could be caused by different preferences amongst sub-populations in the types of professionals considered and preferred when seeking help, but this deserves further investigation. In this Czech population, it seems that younger people prefer help from a psychologist whereas older people tend to seek a GP.

Our sample additionally shows that people living in non-urban areas are more willing to seek care from a psychiatrist, yet urban residence enables the utilization of MHS. A recent systematic review found no association between urban versus rural residents in help-seeking [28], but less is known how the type of residence influences which professionals help seekers prefer to contact. We speculate that people in the countryside may not differ in their objective need to see psychiatrists, but this type of care is not available to them. The lack of the association of MHS utilization with factors related to family structure may be explained by evidence that families are a great source of both support and distress with the potential to enable, but also can deter MHS utilization $[29,30]$.
As opposed to previous studies conducted in other countries [31,32], the present analysis shows that education was unrelated to utilization of MHS in the Czech Republic, but did influence which professional individuals were willing to seek help from. Specifically, our study found an association of higher education with greater willingness to seek help from a psychologist. The fact that some people classified as having a mental disorder report willingness to seek a mental health professional, but did not use any MHS, deserves further attention to deeper understand the mechanisms and barriers to help-seeking. While the lack of availability of desired professionals is a great obstacle, the inability to attribute personal problems as symptoms of mental illness plays a major role in the Czech context.

We found that self-identification as having a mental illness is associated with greater willingness to seek help from mental health professionals, which mirrors results from a study of untreated persons with mental health problems in Germany [8]. Self-identification has previously been linked to stigma: negative stigmatizing attitudes towards persons with mental disorders decrease the likelihood for individuals considering the possibility that what they are experiencing could be a sign of a mental illness [33]. It has also been shown that self-identification as having a mental illness increases the risk of experiencing stigma and selfstigma [34]. Decreasing self-stigma of persons with mental illness and increasing mental health literacy within lay persons could facilitate appraisal of own mental health problems and improve help-seeking.

We propose several strategies that could help reduce the treatment gap for mental disorders in the Czech Republic. There is a need for more accessible and equitable MHS as well as implementation of mental health promotion and stigma reduction programmes in rural areas. Decentralisation of MHS could provide the sub-population of rural residents willing to seek help from psychiatrists with local services and contribute to narrowing the treatment gap associated with residence. The influence of family members may be important for the identification and treatment of mental illness as they are usually in the closest contact with the affected individuals. Focusing on stigma reduction could both increase self-identification of mental health problems, as well as increasing the positive role of family members in promoting helpseeking. Family psycho-education should be available in order to overcome negative beliefs about mental health care and to provide relevant information, emotional support and to teach skills to manage mental illness. 
It has been suggested that language is an important component within mental health promotion interventions for men [35]. Using expressions promoting strength, flexibility, endurance, resilience and problem-solving capacity, focusing on the connection between mind and body as well as targeted interventions in the workplace have been used as strategies for mental health promotion for men [35]. Finally, as the GPs are the most frequently approached professionals for mental health issues, their training to detect and refer patients to appropriate MHS could be a significant way to increase MHS use for those needing treatment.

This study has several limitations. Even though studies suggest that the instrument M.I.N.I. has good validity and reliability [3], it may still have a lower accuracy is classification of some diagnoses [36]. Furthermore, the results of our study are generalizable only to community-dwelling individuals. As individuals institutionalized due to a mental illness are not included in CZEMS, this may overestimate the extent of the treatment gap we found. In addition, the classification of mental disorders in this study is made based on the presence of current symptoms. Thus, persons diagnosed with mental disorders who are currently treated and well-compensated are not included in the analysis, which further overestimates the treatment gap presented in this study.

On the other hand, of notable concern is that the number of persons receiving evidence-based care is likely to be even lower than the treatment gap operationalized by contact with MHS. Future studies should investigate in depth the extent of the disparity between individuals with prevalent mental disorders and the coverage and quality associated with those who receive evidence-based treatment, both in institutions as well as in the community to further inform decision-making in service provision. Furthermore, the extremely high treatment gap for alcohol use disorders deserves further attention in future studies.

To the best of our knowledge, this study is unique in the region of Central and Eastern Europe, providing up-to-date information about the extent of the treatment gap and associated factors based on a nationally representative sample of well-characterized adults. Taking into consideration our findings and the broader literature on closing the treatment gap for mental disorders, we recommend prioritization of nation-wide initiatives and interventions aiming to increase mental health literacy and access to MHS and reduce stigmatization of mental illness, strengthened through targeted interventions specifically for men and rural residents. To decrease the treatment gap of mental disorders in rural areas, where the mental health services are scarce, training of GPs and multisectoral collaboration between GPs and the MHS should be a priority. This would also promote a decrease in the stigma associated with mental disorders.

\section{Funding}

The authors were supported by the project "Sustainability for the National Institute of Mental Health" (grant L01611), with financial support from the Ministry of Education, Youth and Sports of the Czech Republic.

\section{Author contribution}

PC is the guarantor of the study. PC, PW, AK, AA, and ET contributed to the design of the study. PC, TF, KM and ZC performed the data analysis. PC, AK, AA, and ET created the draft of the manuscript. GS and PW critically commented the draft. PC, PW and AK finalized the manuscript.

Data Availability The authors have full access to the study data. Access to the data may be given by contacting the correspondence author.

\section{Declaration of interest}

None.

\section{Acknowledgements}

None.

\section{Appendix A. Supplementary data}

Supplementary material related to this article can be found, in the online version, at doi:https://doi.org/10.1016/j.eurpsy.2019.04.003.

\section{References}

[1] Pec O. Mental health reforms in the Czech Republic. Bjpsych Int 2018;1-3.

[2] Hoschl C, Winkler P, Pec O. The state of psychiatry in the Czech Republic. Int Rev Psychiatry (Abingdon, Engl) 2012;24:278-85.

[3] Winkler P, Formanek T, Mlada K, Cermakova P. The CZEch Mental health Study (CZEMS): Study rationale, design, and methods. Int J Methods Psychiatr Res 2018;e1728.

[4] Krupchanka D, Mlada K, Winkler P, Khazaal Y, Albanese E. Mortality in people with mental disorders in the Czech Republic: a nationwide, register-based cohort study. Lancet Public Health 2018;3:e289-95.

[5] Patel V, Maj M, Flisher AJ, De Silva MJ, Koschorke M, Prince M. Reducing the treatment gap for mental disorders: a WPA survey. World Psychiatry 2010;9:169-76.

[6] Twomey CD, Baldwin DS, Hopfe M, Cieza A. A systematic review of the predictors of health service utilisation by adults with mental disorders in the UK. BMJ Open 2015;5:e007575.

[7] Andrade LH, Alonso J, Mneimneh Z, Wells J, Al-Hamzawi A, Borges G, et al. Barriers to mental health treatment: results from the WHO World Mental Health surveys. Psychol Med 2014;44:1303-17.

[8] Schomerus G, Stolzenburg S, Freitag S, Speerforck S, Janowitz D, Evans-Lacko S, et al. Stigma as a barrier to recognizing personal mental illness and seeking help: a prospective study among untreated persons with mental illness. Eur Arch Psychiatry Clin Neurosci 2018;1-11.

[9] Winkler P, Krupchanka D, Roberts T, Kondratova L, Machu V, Hoschl C, et al. A blind spot on the global mental health map: a scoping review of 25 years' development of mental health care for people with severe mental illnesses in central and eastern Europe. Lancet Psychiatry 2017:4:634-42.

[10] Cermakova P, Formanek T, Kagstrom A, Winkler P. Socioeconomic position in childhood and cognitive aging in Europe. Neurology 2018.

[11] Sheehan DV, Lecrubier Y, Sheehan KH, Amorim P, Janavs J, Weiller E, et al The Mini-International Neuropsychiatric Interview (M.I.N.I.): the development and validation of a structured diagnostic psychiatric interview for DSM-IV and ICD-10. J Clin Psychiatry 1998;59(Suppl (20)) 22 33:quiz 4-57.

[12] Bobak M, Room R, Pikhart H, Kubinova R, Malyutina S, Pajak A, et al. Contribution of drinking patterns to differences in rates of alcohol related problems between three urban populations. J Epidemiol Community Health 2004;58:238-42.

[13] Demyttenaere K, Bruffaerts R, Posada-Villa J, Gasquet I, Kovess V, Lepine JP, et al. Prevalence, severity, and unmet need for treatment of mental disorders in the World Health Organization World Mental Health Surveys. JAMA 2004;291:2581-90.

[14] McGrath JJ, Charlson F, Whiteford HA. Challenges and options for estimating the prevalence of schizophrenia, psychotic disorders, and bipolar disorders in population surveys. 2016.

[15] Kohn R, Saxena S, Levav I, Saraceno B. The treatment gap in mental health care. Bull World Health Organ 2004;82:858-66.

[16] Horackova K, Kopecek M, Machu V, Kagstrom A, Aarsland D, Motlova LB, et al. Prevalence of late-life depression and gap in mental health service use across European regions. Eur Psychiatry 2019;57:19-25.

[17] Enache D, Fereshtehnejad SM, Kareholt I, Cermakova P, Garcia-Ptacek S, Johnell K, et al. Antidepressants and mortality risk in a dementia cohort: data from SveDem, the Swedish Dementia Registry. Acta Psychiatr Scand 2016;134:430-40.

[18] Secnik J, Cermakova P, Fereshtehnejad SM, Dannberg P, Johnell K, Fastbom J, et al. Diabetes in a large dementia cohort: clinical characteristics and treatment from the swedish dementia registry. Diabetes Care 2017;40:1159-1166

[19] Üstün TB, Kostanjsek N, Chatterji S, Rehm J. Measuring health and disability: manual for WHO disability assessment schedule WHODAS 2.0. World Health Organization; 2010.

[20] Schomerus G, Auer C, Rhode D, Luppa M, Freyberger HJ, Schmidt S. Personal stigma, problem appraisal and perceived need for professional help in currently untreated depressed persons. J Affect Disord 2012;139:94-7.

[21] Alonso J, Liu Z, Evans-Lacko S, Sadikova E, Sampson N, Chatterji S, et al Treatment gap for anxiety disorders is global: results of the World Mental Health Surveys in 21 countries. Depress Anxiety 2018;35:195-208. 
[22] UNODC. World drug report. New York: United Nations Office for Drugs and Crime; 2018.

[23] Kovess-Masfety V, Boyd A, Van de Velde S, De Graaf R, Vilagut G, Haro JM, et al. Are there gender differences in service use for mental disorders across countries in the European Union? Results from the EU-World Mental Health survey. J Epidemiol Community Health 2014;68:649-56.

[24] Pattyn E, Verhaeghe M, Bracke P. The gender gap in mental health service use. Soc Psychiatry Psychiatr Epidemiol 2015;50:1089-95.

[25] Mackenzie C, Gekoski W, Knox V. Age, gender, and the underutilization of mental health services: the influence of help-seeking attitudes. Aging Ment Health 2006; 10:574-82.

[26] Yoshikawa E, Taniguchi T, Nakamura-Taira N, Ishiguro S, Matsumura H. Factors associated with unwillingness to seek professional help for depression: a webbased survey. BMC Res Notes 2017;10:673.

[27] Cermakova P, Szummer K, Johnell K, Fastbom J, Winblad B, Eriksdotter M, et al. Management of acute myocardial infarction in patients with dementia: data from SveDem, the swedish dementia registry. J Am Med Dir Assoc 2017;18:19-23.

[28] Roberts T, Miguel Esponda G, Krupchanka D, Shidhaye R, Patel V, Rathod S. Factors associated with health service utilisation for common mental disorders: a systematic review. BMC Psychiatry 2018;18:262.

[29] Rowe J. Great expectations: a systematic review of the literature on the role of family carers in severe mental illness, and their relationships and engagement with professionals. J Psychiatr Ment Health Nurs 2012;19:70-82.
[30] Cermakova P, Nelson M, Secnik J, Garcia-Ptacek S, Johnell K, Fastbom J, et al. Living alone with alzheimer's disease: data from SveDem, the swedish dementia registry. J Alzheimers Dis 2017;58:1265-72.

[31] Evans-Lacko S, Aguilar-Gaxiola S, Al-Hamzawi A, Alonso J, Benjet C, Bruffaerts $\mathrm{R}$, et al. Socio-economic variations in the mental health treatment gap for people with anxiety, mood, and substance use disorders: results from the WHO World Mental Health (WMH) surveys. Psychol Med 2018;48:1560-71.

[32] Wang PS, Aguilar-Gaxiola S, Alonso J, Angermeyer MC, Borges G, Bromet EJ, et al. Use of mental health services for anxiety, mood, and substance disorders in 17 countries in the WHO world mental health surveys. Lancet 2007;370:841-50.

[33] Stolzenburg S, Freitag S, Evans-Lacko S, Muehlan H, Schmidt S, Schomerus G. The stigma of mental illness as a barrier to self labeling as having a mental illness. J Nerv Ment Dis 2017;205:903-9.

[34] Cruwys T, Gunaseelan S. "Depression is who I am": mental illness identity, stigma and wellbeing. J Affect Disord 2016;189:36-42.

[35] Seaton CL, Bottorff JL, Jones-Bricker M, Oliffe JL, DeLeenheer D, Medhurst K. Men's mental health promotion interventions: a scoping review. Am J Mens Health 2017; $11: 1823-37$.

[36] Lecrubier Y, Sheehan DV, Weiller E, Amorim P, Bonora I, Sheehan KH, et al. The Mini International Neuropsychiatric Interview (MINI). A short diagnostic structured interview: reliability and validity according to the CIDI. Eur Psychiatry 1997;12:224-31. 